\title{
Metastatic pattern and prognosis of gastrointestinal stromal tumor (GIST): a SEER-based analysis
}

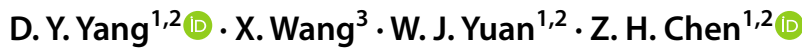

Received: 8 January 2019 / Accepted: 14 March 2019 / Published online: 23 March 2019

(c) The Author(s) 2019

\begin{abstract}
Purpose This SEER-based study aimed to explore and analyze the relationship of metastasis of liver, lung and bone of GIST patients and their prognosis.

Methods The data of GIST patients were from Surveillance, Epidemiology, and End Results (SEER) database from 2010 to 2015 and all the statistical analyses were conducted by statistical software package SPSS (Version 22.0).

Results A total of 4224 GIST patients were identified, of which 388 (9.19\%) patients with liver metastasis, $20(0.47 \%)$ patients with bone metastasis and $32(0.76 \%)$ patients with lung metastasis. There was no significant difference of risk of bone or lung metastasis between patients with and without liver metastasis $(P=0.935)$. The median overall survival of patients with liver, bone, or lung metastasis was, respectively, 49 months, 18 months, and 20 months, which were all shorter than that of patients without metastasis. The overall survival of patients with both liver and bone metastasis and those with metastasis of all three sites was not significantly different from that of patients with only liver metastasis. The multivariate analysis showed age of less than 65 years, female patients, married status and receiving surgery were all the beneficial factors for prognosis of GIST patients with liver metastasis.

Conclusions Patients with metastasis had a poorer prognosis than those without. Liver metastasis might have no relationship with bone or lung metastasis and liver might play a more dominant role than the other two sites in the prognosis of GIST patients with metastasis. So, more attention should be paid to liver status in diagnosis and treatment of GIST patients.
\end{abstract}

Keywords Gastrointestinal stromal tumor $\cdot$ Metastasis $\cdot$ Prognosis $\cdot$ SEER

\section{Introduction}

Gastrointestinal stromal tumor (GIST) is the most common mesenchymal tumor of the gastrointestinal tract, accounting for nearly $1-3 \%$ of all malignant gastrointestinal tumors [23]. GIST was thought to originate from interstitial cells of Cajal (ICC), a pace-maker cell that regulated gut peristalsis [29]. The molecular pathogenesis of GIST was regarded to be closely related to mutation of KIT and PDGFRA gene

Z.H. Chen

zihuac@outlook.com

1 Department of General Surgery, Xiangya Hospital of Central South University, \#87 Xiangya Road, Changsha 410008, Hunan Province, People's Republic of China

2 Hunan Key Laboratory of Precise Diagnosis and Treatment of Gastrointestinal Tumor, Changsha, China

3 Department of General Surgery, Shijitan Hospital of Capital Medical University, Beijing, China
[18]. The incidence of GIST was reported as 10-15 cases per million people per year in most studies [31]. Stomach (55.6\%) and small intestinal $(31.8 \%)$ are the most common primary sites of GIST [31].

Like other tumors, GIST can also be metastasized to other sites of body. Liver metastasis and peritoneal dissemination are the two main metastatic pattern of GIST and besides, lung, bone, brain, pleura and lymph nodes are also the metastatic sites but less common [35]. Although bone or lung metastasis of GIST is rare, there were still several cases that had been reported $[1,3,33,37]$. However, the small sample size led to nearly no studies that analyzed and summarized the relationship of those metastatic locations and their influential and prognostic factors.

The Surveillance, Epidemiology and End Results (SEER) database started to release the data of metastasis including liver, bone, lung and brain in 2010. Therefore, this study aimed to systematically analyze the metastatic pattern of GIST and its prognostic impact on GIST by using SEER 
database from a macroscopic angle in the general population in order to provide some useful suggestions for clinical diagnosis and treatment.

\section{Methods}

\section{Database}

The data were from the Surveillance, Epidemiology and End Results (SEER) database which collected survival data of patients with cancer nearly covering $28 \%$ of the American population. This database is available for public cancer studies and we have got the permission to obtain research data from the SEER database (Reference Number 14660Nov2017) and we have also promised not to identify any individual. This research was approved by our Xiangya Hospital, Central South University.

\section{Cohort identification}

The National Cancer Institute SEER*Stat software (Version 8.3.5) was used to identify patients. The patients with GIST were selected by the following criteria: (1) CS schema v0204+: "GISTAppendix" or "GISTColon" or "GISTEsophagus" or "GISTPeritoneum" or "GISTRectum" or "GISTSmallIntestine" or "GISTStomach"; (2) Histologic Type ICD-O-3: 8936; (3) Year of diagnosis ranged from 2010 to 2015; (4) metastatic condition of bone, brain, liver, or lung should be obtained; (5) survival state and survival time must be known.

\section{Outcome variables}

In our study, the main variables were available in the database including the bone, brain, liver, and lung metastasis state and the main outcomes were 5 -year overall survival (OS) and cause-specific survival (CSS) (2-year OS or CSS in some special conditions). Cause-specific survival was defined as deaths because of GIST instead of other causes. Besides, we also selected the following variables including age at diagnosis, race, sex, marital status, insurance status, tumor site, tumor grade, $\mathrm{T}$ and $\mathrm{N}$ stage, and surgery.

For age at diagnosis, we separated the population into 2 groups: less than 64 years old and more than 65 years old. Marital status was categorized into 3 groups: married, unmarried (including divorced, separated, single, and widowed) and unknown. Insurance status was categorized into 3 groups: insured (including any Medicaid and insured/no specifics), uninsured, and unknown. Tumor site was categorized into 5 groups: stomach, small intestinal, colon, rectum and others (including appendix, cecum, esophagus, retroperitoneum, peritoneum, omentum and mesentery).

\section{Statistical methods}

Comparisons of categorical variables were analyzed by using the Chi-square test and OS or CSS curves were showed by applying Kaplan-Meier plots and their difference comparison was analyzed via log-rank test. The risk factors of prognosis were analyzed by using multivariate Cox proportional hazard models. All the statistical analyses were performed using statistical software package SPSS (Version 22.0). Statistical significance was defined as twosided $P<0.05$.

\section{Results}

\section{Patients characteristics}

The total of 4224 patients were included in this study group, of which 2036 were women $(48.2 \%)$ and 2188 were men $(51.8 \%)$. The average age was 64 years old. The AJCC stage from I to IV were $38.1 \%, 13.2 \%, 13.9 \%$, and $17.0 \%$, respectively.

\section{Metastatic pattern}

Table 1 shows the three metastatic conditions and their combination. In the total 4224 patients, there were 3817 $(90.36 \%)$ patients with no metastasis. The general rate of metastasis to liver, bone and lung were $9.19 \%, 0.47 \%$, and $0.76 \%$, respectively, and in detail, the number of patients with metastasis of only liver, lung, and bone was 362 (8.57\%), $10(0.24 \%)$, and 6(0.14\%), respectively. Besides,

Table 1 Metastatic pattern

\begin{tabular}{lrll}
\hline & Number (\%) & 5-year OS (95\% CI) & $\begin{array}{l}\text { Median } \\
\text { OS } \\
\text { (months) }\end{array}$ \\
\hline No metastasis & $3817(90.36)$ & $\begin{array}{l}75.80 \%(73.64- \\
77.96 \%)\end{array}$ & $>60$ \\
One site & & & \\
Bone & $6(0.14)$ & $33.33 \%(0-70.93 \%)$ & 8 \\
Liver & $362(8.57)$ & $42.00 \%(33.38-$ & 50 \\
& & $50.62 \%)$ & \\
Lung & $10(0.24)$ & $33.33 \%(0-67.01 \%)$ & 15 \\
Two sites & & & 20 \\
Liver+lung & $15(0.36)$ & 0 & 40 \\
Liver+bone & $7(0.17)$ & 0 & 4 \\
Bone + lung & $3(0.07)$ & $33.33 \%(0-86.61 \%)$ & 4 \\
Three sites & & & 10 \\
Liver+lung + bone & $4(0.09)$ & $37.50 \%(0-93.56 \%)$ & 10 \\
\hline
\end{tabular}

$O S$ overall survival, $C I$ confidence interval 
there were $15(0.36 \%), 7(0.17 \%), 3(0.07 \%)$ and $4(0.09 \%)$ patients who had metastasis of both liver and lung, of both liver and bone, of both lung and bone, and of all three sites, respectively. Because only 1 patient $(0.02 \%)$ had brain metastasis, so the discussion about brain metastasis will be omitted in our study. Clinical features of metastasis of liver, bone and lung for GIST patients are shown in Table 2.

\section{Liver metastasis}

Liver is the most easily metastasized site, which had the highest percentage metastasis among the three sites. The percentage of liver metastasis in men $(10.6 \%)$ was higher than women (7.6\%). For the common site, colon (11.9\%) had the highest percentage of liver metastasis and the percentage of stomach $(9.1 \%)$ and small intestinal $(8.7 \%)$ was approximate. For the tumor grade, undifferentiated and poorly differentiated tumors were the most two types, which had $16.2 \%$ and $13.9 \%$, respectively. Besides, $\mathrm{T}$ and $\mathrm{N}$ stage and surgery $(P<0.001)$ were also the significant risk factors for the liver metastasis of GIST. However, other factors such as age, race, marital status, and insurance status were not found significant between patients with and without liver metastasis.

\section{Lung and bone metastasis}

The general results were similar to liver metastasis, but with a few differences. For the sex, bone or lung metastasis both showed no significance in patients. For the site, there was no significant difference in patients with or without bone metastasis $(P=0.091)$, but lung metastasis still showed significant result $(P=0.015)$. For the tumor grade, neither of them showed significant differences between patients with or without metastasis. Besides, the factors like $\mathrm{T}$ and $\mathrm{N}$ stage and surgery all had significant results and other factors like age, race, marital status, and insurance status all showed insignificant differences among patients, which were similar to the results of liver metastasis.

\section{Risk of bone or lung metastasis in patients with and without liver metastasis}

We compared the risk of bone or lung metastasis or their combination in patients with and without liver metastasis. The results showed that although the percentage of bone or lung metastasis in patients with liver metastasis was a little higher than those without, the difference was not significant (bone: $0.2 \%$ vs $0.1 \%$, lung: $0.4 \%$ vs $0.2 \%$, bone + lung: $0.1 \%$ vs $0.1 \%, P=0.935$ ) (Fig. 1).

\section{Survival analysis}

\section{Overall survival (OS) between patients with and without metastasis}

There was a significant difference between patients with and without metastasis, as shown in the OS Kaplan-Meier curve (Fig. 2). The patients without liver metastasis had a better 5 -year OS than those with liver metastasis (OS: $75.5 \%$ vs $39.9 \%, P<0.001$, Fig. 2a). The similar results were also seen in patients with and without bone or lung metastasis (bone: $72.6 \%$ vs $33.7 \%, P<0.001$, Fig. 2 b; lung: $72.8 \%$ vs $19.7 \%$, $P<0.001$, Fig. $2 \mathrm{c}$ ). The median overall survival time for patients with liver, bone, and lung metastasis was 49 months, 18 months, and 20 months, respectively.

\section{Cause-specific survival (CSS) between patients with and without metastasis}

The cause-specific survival in patients with or without metastasis also had a significantly different result (Fig. 2). Patients with liver metastasis had a lower 5-year CSS than those without (CSS: $47.6 \%$ vs $86.9 \%, P<0.001$, Fig. 2 d). Also, patients with bone or lung metastasis died earlier than those without (bone: $37.6 \%$ vs $83.5 \%, P=0.001$, Fig. 2 e; lung: $35.2 \%$ vs $83.7 \%, P<0.001$, Fig. 2f). The median cause-specific survival time for patients with liver, bone, and lung was 54 months, 40 months, and 25 months, respectively.

\section{Overall survival of patients with liver metastasis and its combination}

We also analyzed the overall survival of patients with liver metastasis and its combination (Fig. 3). The result showed that patients with only liver metastasis had a better 5-year overall survival than those with both liver and lung metastasis (2-year OS: $69.3 \%$ vs $42.4 \%, P<0.001$, Fig. 3a) and the median overall survival time for patients with only liver metastasis was 50 months, which was longer than 20 months of patients with liver and lung metastasis. However, such significant difference was not seen between patients with liver metastasis and those with liver and bone metastasis (2-year OS: $69.3 \%$ vs $62.5 \%, P=0.537$, Fig. $3 b$ ), and between patients with liver and lung metastasis and those with liver and bone metastasis ( $42.4 \%$ vs $62.5 \%, P=0.298$, Fig. 3c). Even if the patients had three sites of metastasis (liver and bone and lung), the difference of overall survival between them was also insignificant ( $P=0.183$, Fig. 3d). 
Table 2 Clinical features and metastasis sites for GIST

\begin{tabular}{|c|c|c|c|c|c|c|c|c|c|}
\hline & \multicolumn{3}{|l|}{ Bone $(\%)$} & \multicolumn{3}{|l|}{ Liver $(\%)$} & \multicolumn{3}{|l|}{ Lung (\%) } \\
\hline & No & Yes & $P$ & No & Yes & $P$ & No & Yes & $P$ \\
\hline Age & & & 0.117 & & & 0.079 & & & 0.112 \\
\hline$<64$ years & 2053 (99.7) & $6(0.3)$ & & $1853(90.0)$ & $206(10.0)$ & & 2048 (99.5) & $11(0.5)$ & \\
\hline$>65$ years & $2151(99.4)$ & $14(0.6)$ & & 1983 (91.6) & $182(8.4)$ & & $2144(99.0)$ & $21(1.0)$ & \\
\hline Race & & & 0.644 & & & 0.208 & & & 0.887 \\
\hline White & $2840(99.5)$ & $14(0.5)$ & & 2595 (90.9) & $259(9.1)$ & & $2832(99.2)$ & $22(0.8)$ & \\
\hline Black & 775 (99.4) & $5(0.6)$ & & $696(89.2)$ & $84(10.8)$ & & 775 (99.4) & $5(0.6)$ & \\
\hline Others & 547 (99.8) & $1(0.2)$ & & 505 (92.2) & $43(7.8)$ & & 543 (99.1) & $5(0.9)$ & \\
\hline Unknown & $42(100)$ & $0(0)$ & & $40(95.2)$ & $2(4.8)$ & & $42(100)$ & $0(0)$ & \\
\hline Sex & & & 0.119 & & & 0.001 & & & 0.155 \\
\hline Women & 2030 (99.7) & $6(0.3)$ & & $1881(92.4)$ & $155(7.6)$ & & 2025 (99.5) & $11(0.5)$ & \\
\hline Men & $2174(99.4)$ & $14(0.6)$ & & 1955 (89.4) & 233 (10.6) & & 2167 (99.0) & $21(1.0)$ & \\
\hline Marital status & & & 0.988 & & & 0.236 & & & 0.829 \\
\hline Married & $2362(99.5)$ & $11(0.5)$ & & 2155 (90.8) & $218(9.2)$ & & 2354 (99.2) & $19(0.8)$ & \\
\hline Unmarried & 1615 (99.5) & $8(0.5)$ & & $1467(90.4)$ & $156(9.6)$ & & $1611(99.3)$ & $12(0.7)$ & \\
\hline Unknown & $227(99.6)$ & $1(0.4)$ & & 214 (93.9) & $14(6.1)$ & & 227 (99.6) & $1(0.4)$ & \\
\hline Insurance & & & 0.256 & & & 0.301 & & & 0.472 \\
\hline Insured & 3980 (99.5) & $18(0.5)$ & & 3637 (91.0) & $361(9.0)$ & & 3967 (99.2) & $31(0.8)$ & \\
\hline Uninsured & 149 (98.7) & $2(1.3)$ & & $132(87.4)$ & 19 (12.6) & & $151(100)$ & $0(0)$ & \\
\hline Unknown & 75 (100) & $0(0)$ & & $67(89.3)$ & $8(10.7)$ & & 74 (98.7) & $1(1.3)$ & \\
\hline Site & & & 0.091 & & & 0.028 & & & 0.015 \\
\hline Stomach & 2749 (99.5) & $14(0.5)$ & & 2511 (90.9) & $252(9.1)$ & & 2742 (99.2) & $21(0.8)$ & \\
\hline Small intestinal & 1144 (99.8) & $2(0.2)$ & & $1046(91.3)$ & $100(8.7)$ & & 1142 (99.7) & $4(0.3)$ & \\
\hline Colon & $66(98.5)$ & $1(1.5)$ & & $59(88.1)$ & $8(11.9)$ & & $66(98.5)$ & $1(1.5)$ & \\
\hline Rectum & $110(98.2)$ & $2(1.8)$ & & 106 (94.6) & $6(5.4)$ & & 109 (97.3) & $3(2.7)$ & \\
\hline Others & 135 (99.3) & $1(0.7)$ & & $114(83.8)$ & $22(16.2)$ & & 133 (97.8) & $3(2.2)$ & \\
\hline Grade & & & 0.230 & & & $<0.001$ & & & 0.415 \\
\hline Well & 865 (99.9) & $1(0.1)$ & & $850(98.2)$ & $16(1.8)$ & & 863 (99.7) & $3(0.3)$ & \\
\hline Moderately & $558(99.8)$ & $1(0.2)$ & & $534(95.5)$ & $25(4.5)$ & & $556(99.5)$ & $3(0.5)$ & \\
\hline Poorly & $186(99.5)$ & $1(0.5)$ & & $161(86.1)$ & $26(13.9)$ & & $186(99.5)$ & $1(0.5)$ & \\
\hline Undifferentiated & 264 (99.6) & $1(0.4)$ & & $222(83.8)$ & $43(16.2)$ & & 262 (98.9) & $3(1.1)$ & \\
\hline Unknown & 2331 (99.3) & $16(0.7)$ & & 2069 (88.2) & 278 (11.8) & & $2325(99.1)$ & $22(0.9)$ & \\
\hline T stage & & & 0.012 & & & $<0.001$ & & & \\
\hline T0 & $5(100)$ & $0(0)$ & & $1(20.0)$ & $4(80.0)$ & & $4(80.0)$ & $1(20.0)$ & \\
\hline $\mathrm{T} 1$ & $518(100)$ & $0(0)$ & & 511 (98.6) & $7(1.4)$ & & $518(100)$ & $0(0)$ & \\
\hline $\mathrm{T} 2$ & 1255 (99.7) & $4(0.3)$ & & $1219(96.8)$ & $40(3.2)$ & & 1255 (99.7) & $4(0.3)$ & \\
\hline $\mathrm{T} 3$ & 1140 (99.6) & $5(0.4)$ & & $1056(92.2)$ & $89(7.8)$ & & 1141 (99.7) & $4(0.3)$ & \\
\hline $\mathrm{T} 4$ & 879 (99.5) & $4(0.5)$ & & $761(86.2)$ & $122(13.8)$ & & 872 (98.8) & $11(1.2)$ & \\
\hline TX & 404 (98.3) & $7(1.7)$ & & $286(69.6)$ & $125(30.4)$ & & $399(97.1)$ & $12(2.9)$ & \\
\hline Unknown & $3(100)$ & $0(0)$ & & $2(66.7)$ & $1(33.3)$ & & $3(100)$ & $0(0)$ & \\
\hline N stage & & & $<0.001$ & & & $<0.001$ & & & $<0.001$ \\
\hline No & 4042 (99.6) & $15(0.4)$ & & 3719 (91.7) & $338(8.3)$ & & 4033 (99.4) & $24(0.6)$ & \\
\hline N1 & 159 (97.0) & $5(3.0)$ & & $115(70.1)$ & 49 (29.9) & & $156(95.1)$ & $8(4.9)$ & \\
\hline Unknown & $3(100)$ & $0(0)$ & & $2(66.7)$ & $1(33.3)$ & & $3(100)$ & $0(0)$ & \\
\hline Surgery & & & $<0.001$ & & & $<0.001$ & & & \\
\hline Yes & 3457 (99.9) & $5(0.1)$ & & 3305 (95.5) & $157(4.5)$ & & $3456(99.8)$ & $6(0.2)$ & \\
\hline No & 741 (98.0) & $15(2.0)$ & & $525(69.4)$ & $231(30.6)$ & & 730 (96.6) & $26(3.4)$ & \\
\hline Unknown & $6(100)$ & $0(0)$ & & $6(100)$ & $0(0)$ & & $6(100)$ & $0(0)$ & \\
\hline
\end{tabular}




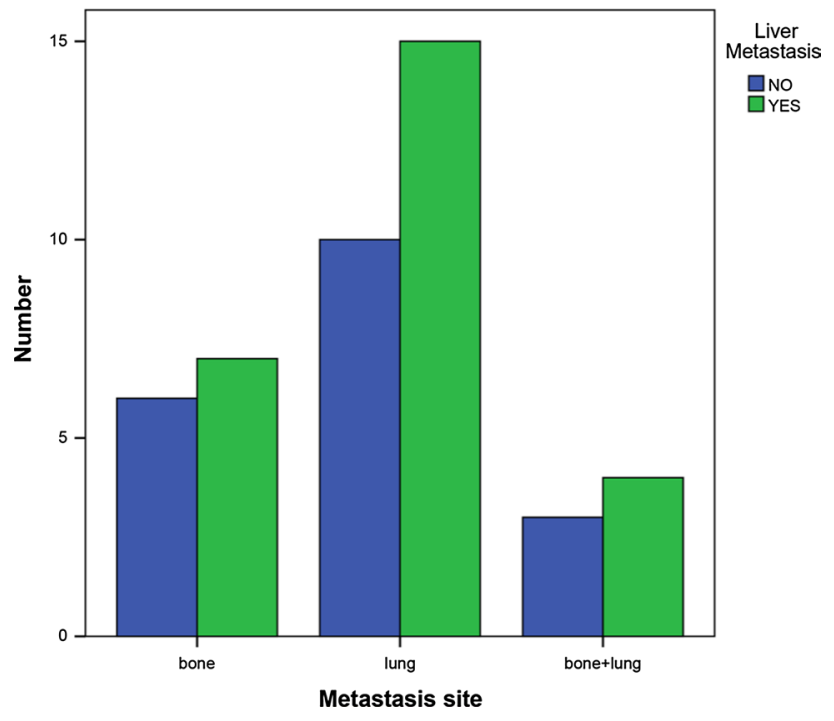

Fig. 1 Comparison of metastasis rate of bone or lung in patients with and without liver metastasis $(P=0.935)$

\section{Prognostic factors for GIST patients with liver metastasis}

Since liver is the most common site to be metastasized, we further analyzed some possible prognostic factors for GIST patients with liver metastasis. We selected several variables in the Cox hazards model, which had been tested to have potential relation to the survival in the univariate analysis $(P<0.10)$, such as age, race, sex, marital status, $\mathrm{T}$ stage and surgery, etc. Among them, age, sex, marital status and surgery were all the independent prognostic factors for the overall survival of patients with GIST. And patients of over 65 years old ( $\mathrm{HR}=2.575,95 \% \mathrm{CI}: 1.826-3.632)$ and male patients $(\mathrm{HR}=1.652,95 \% \mathrm{CI}: 1.155-2.362)$ had a higher risk of survival reduction in the analysis; however, married patients (HR $=0.520,95 \%$ CI: $0.372-0.727)$ and patients who received surgery (HR $=0.601,95 \%$ CI: $0.419-0.860$ ) had a better prognosis. Other insignificant variates were not included in the Cox analysis model (Table 3).

\section{Discussion}

The results showed that the rate of metastasis to liver, bone and lung were $9.19,0.47$, and $0.76 \%$, respectively. The rate of liver metastasis in our study was not as high as that of some previous studies, which was $20-25 \%$ at diagnosis of GIST [25]. Similarly, the rate of bone metastasis was also lower than $3.2-5.5 \%$ of some studies reported $[3,16]$. As for lung metastasis, only some sporadic cases of GIST with lung metastasis were reported and Nilsson et al. [26] had (a) os of liver metastasis

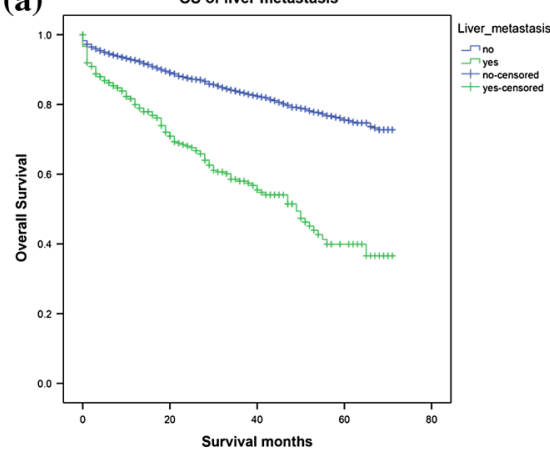

(d)

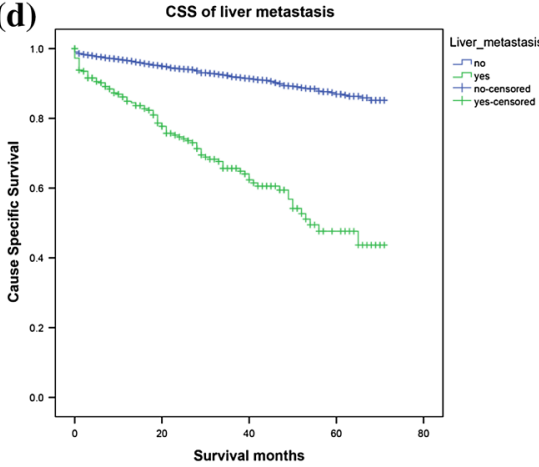

(b)

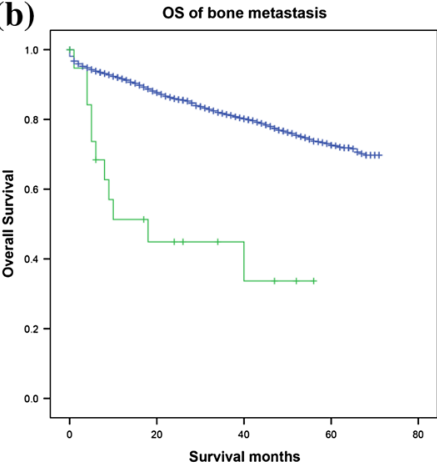

(e)

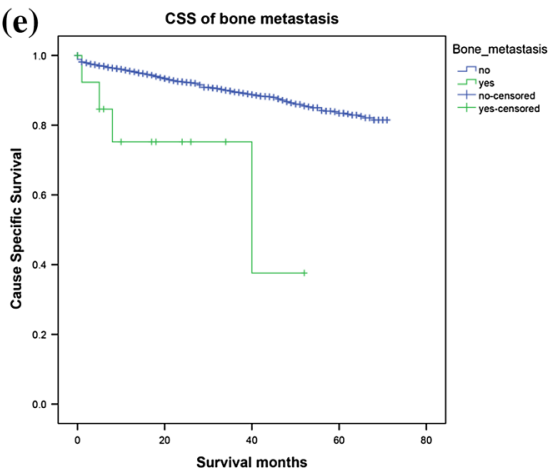

(c) os of lung metastasis

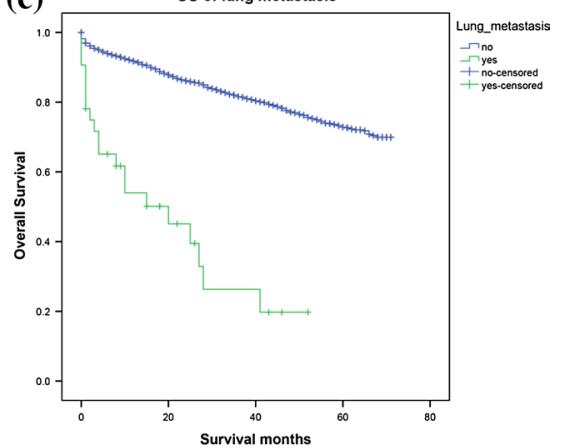

(f)

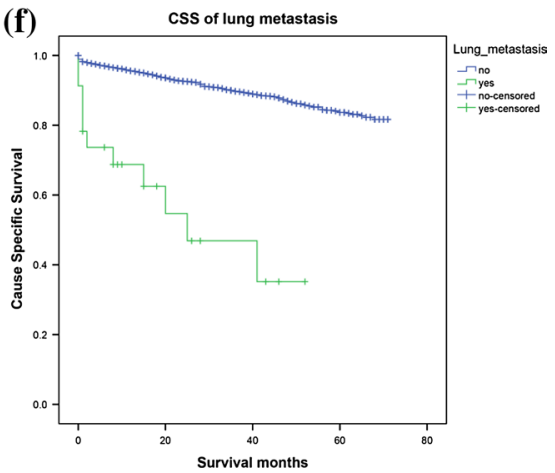

Fig. 2 Overall survival (OS) of patients with and without liver metastasis, $P<0.001$ (a), with and without bone metastasis, $P<0.001$ (b), with and without lung metastasis, $P<0.001$ (c); cause-specific sur- vival (CSS) of patients with and without liver metastasis, $P<0.001$ (d), with and without bone metastasis, $P=0.001$ (e); with and without lung metastasis, $P<0.001$ (f) 

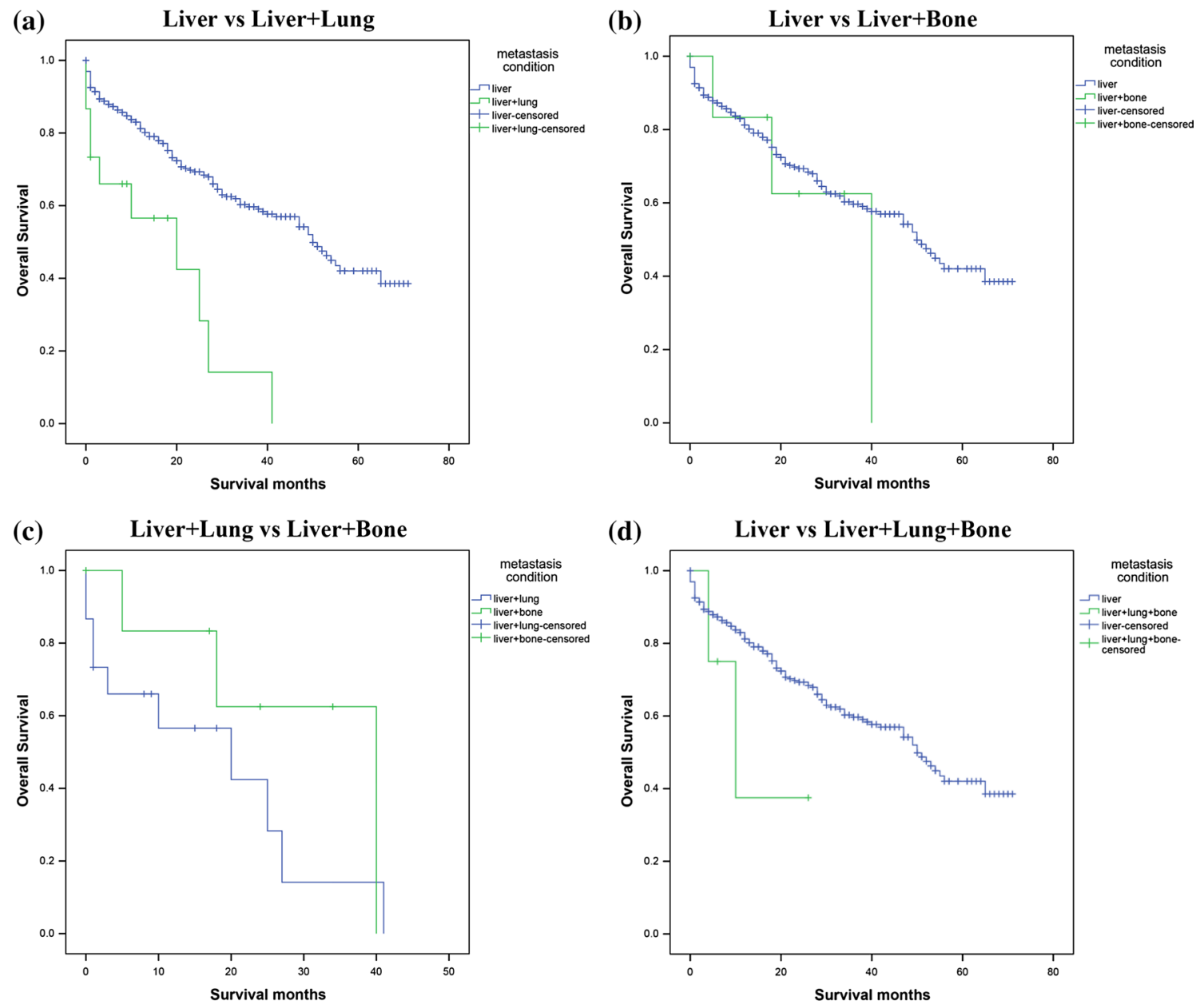

Fig. 3 Overall survival (OS) of patients with only liver metastasis and patients with both liver and lung metastasis, $P<0.001$ (a), OS of patients with only liver metastasis and patients with both liver and bone metastasis, $P=0.537$ (b), OS of patients with liver and lung

reported that only one out of 259 patients $(0.39 \%)$ with GIST developed lung metastasis. Such differences between our results and previous studies might be related to the sample size and potential bias. However, the rate of liver metastasis was still much higher than the other two sites, in which case some appropriate modalities like MRI to examine the liver lesions should be recommended as a routine [20]. Moreover, although it is conventionally acknowledged that gastrointestinal tumors can metastasize to liver via portal vein most commonly and they can also metastasize to other sites like lung or bone directly or indirectly via blood or lymph system, our results showed that there were not significant differences of risks of bone or lung metastasis between patients with and without liver metastasis, which suggested that liver metastasis and bone or lung metastasis might be the independent events to each other. So, considering such low metastasis rate and irrelativity to liver metastasis, it is metastasis and patients with liver and bone metastasis, $P=0.298(\mathbf{c})$, OS of patients with only liver metastasis and patients with all the three site metastasis, $P=0.183(\mathbf{d})$

unnecessary to regard screening bone or lung metastasis status as a routine.

Our results showed that men had a higher risk of liver metastasis than women, which is in accordance with the previous studies that showed GIST had a mild male predominance [25, 34]. GIST in different sites could have different incidence [10], which might account for the differences of risks in liver and lung metastasis. For the tumor grade, the majority of GIST appeared not to be well differentiated [22, $32]$, so the percentage of poorly differentiated (13.9\%) and undifferentiated (16.2\%) GIST patients with liver metastasis in our study were also much higher than that of well $(1.8 \%)$ and moderately (4.5\%) differentiated ones. Besides, $\mathrm{T}$ stage was also a significant factor for the risk of metastasis. Several previous studies had reported that tumors with the size of $>5 \mathrm{~cm}$ had more possibility to metastasize $[6,13$, 23]. So, we compared the tumors of $\mathrm{T} 3(5-10 \mathrm{~cm})$ and $\mathrm{T} 4$ $(>10 \mathrm{~cm})$ with tumors of T0, T1 $(<2 \mathrm{~cm})$, and T2 $(2-5 \mathrm{~cm})$ 
Table 3 Univariate and multivariate analyses for GIST patients with liver metastasis

\begin{tabular}{|c|c|c|c|c|}
\hline & \multicolumn{2}{|l|}{ Univariate analysis } & \multicolumn{2}{|l|}{ Multivariate analysis } \\
\hline & 5-year OS & $P$ value & $\mathrm{HR}(95 \% \mathrm{CI})$ & $P$ value \\
\hline Age & & $<0.001$ & & \\
\hline$<65$ & $53.10 \%(41.14-65.06 \%)$ & & 1 & 1 \\
\hline$>65$ & $25.90 \%(15.51-35.29 \%)$ & & $2.575(1.826-3.632)$ & $<0.001$ \\
\hline Race & & 0.022 & & \\
\hline Black & $19.60 \%(3.33-35.87 \%)$ & & - & 1 \\
\hline White & $45.70 \%(35.31-56.09 \%)$ & & - & 0.278 \\
\hline Others & $42.70 \%(20.55-64.85 \%)$ & & - & 0.485 \\
\hline Unknown & $0.00 \%(0)$ & & - & 0.845 \\
\hline Sex & & 0.070 & & \\
\hline Female & $53.40 \%(40.27-66.53 \%)$ & & 1 & 1 \\
\hline Male & $35.10 \%(25.69-44.51 \%)$ & & $1.652(1.155-2.362)$ & 0.006 \\
\hline Marital status & & 0.001 & & \\
\hline Unmarried & $25.80 \%(13.26-38.34 \%)$ & & 1 & 1 \\
\hline Married & $45.00 \%(37.42-58.58 \%)$ & & $0.520(0.372-0.727)$ & $<0.001$ \\
\hline Unknown & $85.70 \%(67.28-100 \%)$ & & $0.330(0.081-1.346)$ & 0.122 \\
\hline T stage & & 0.001 & & \\
\hline T0 & $0.00 \%(0)$ & & - & 1 \\
\hline $\mathrm{T} 1$ & $44.40 \%(0.89-87.91 \%)$ & & - & 0.585 \\
\hline $\mathrm{T} 2$ & $0.00 \%(0)$ & & - & 0.184 \\
\hline $\mathrm{T} 3$ & $61.80 \%(46.71-76.89 \%)$ & & - & 0.118 \\
\hline $\mathrm{T} 4$ & $39.00 \%(24.30-53.70 \%)$ & & - & 0.482 \\
\hline TX & $24.60 \%(12.06-37.14 \%)$ & & - & 0.219 \\
\hline Surgery & & 0.001 & & \\
\hline No & $29.50 \%(19.31-39.69 \%)$ & & 1 & 1 \\
\hline Yes & $55.80 \%(42.86-68.74 \%)$ & & $0.601(0.419-0.860)$ & 0.005 \\
\hline
\end{tabular}

$O S$ overall survival, $H R$ hazard ratio, $C I$ confidence interval and we found that it was more likely for tumors of $>5 \mathrm{~cm}$ than $<5 \mathrm{~cm}$ to metastasize only in liver $(10.4 \%$ vs $2.9 \%$, $P<0.001)$ but not in bone $(0.4 \%$ vs $0.2 \%, P=0.279)$ or lung $(0.7 \%$ vs $0.3 \%, P=0.070)$. Although some researches also recommended the tumor size of $2 \mathrm{~cm}$ as a cutoff point for screening the possibility of metastasis [12], our study also proved that only liver metastasis had significant evidence, but not the other two sites. Moreover, it was accessible that patients in N1 stage and patients who did not receive surgery both had a significantly high percentage of metastasis. Therefore, sex, tumor site, tumor grade, tumor size, regional lymph node metastatic condition and surgery were all the risk factors of metastasis.

The median overall survival time of GIST without metastasis was more than 60 months and patients without metastasis survived longer than those with liver, bone, or lung metastasis, which suggested that GIST with metastasis had a poorer prognosis. However, except for liver and lung metastasis, patients with metastasis of liver and bone or with metastasis of all the three sites did not show a significantly worse overall survival than the patients with only liver metastasis. So, the results indicated that liver metastasis might be more significant for the prognosis of GIST than metastasis of the other two sites and the lesions in the liver of GIST patients should be paid more attention.

Since liver metastasis was the most common type of metastasis pattern in GIST patients, we analyzed the relative prognostic factors and our multivariate analysis resulted showed that $<65$ years old, female, married patients, and patients who received surgery might have a better prognosis for GIST with liver metastasis. The poorer prognosis in elder patients might be related to combination with other diseases or reception of less treatment due to higher possibilities of drug side-effects $[5,11]$. The relationship between sex and prognosis was not clear, but might be correlated with more psychological distress in male patients [14]. Our results showed that married status might be a beneficial prognostic factor, which was in accordance with the studies of Song et al. [30] and Chen et al. [7]. The protective function of married status might be related to less psychological burden, earlier diagnosis, better compliance to prescription and even more financial support, etc.[2, 14, 15, 27] It had also been proved that surgery could improve overall survival in GIST patients with metastasis [4, 9, 28]. Interestingly, $\mathrm{T}$ stage 
(especially T3, T4), namely tumor size, was the significant prognostic factor in the univariate analysis (5-year OS T3 vs T4: $61.8 \%$ vs $39.0 \%, P=0.011)$. It had also been reported in previous studies that the tumor size of $>5 \mathrm{~cm}$ was the poor prognostic factor and even tumor size of $>10 \mathrm{~cm}$ meant worse survival [8, 23, 24]. However, our multivariate analysis results showed that tumor size was not a significant prognostic factor in the GISTs with liver metastasis. We guessed it might be related to the following reasons: (1) the larger the tumor size was, the easier the tumor could be detected and the earlier the patients could receive treatment; (2) the larger tumor had a higher risk of metastasis and patients needed to receive other adjuvant therapy like imatinib, a TKI inhibitor [36]; (3) the larger tumor need more extensive resections [21], in which case the tumor might be resected more thoroughly.

To our best knowledge, it is the first study to excavate the metastatic pattern of GIST based on SEER database. However, there are also some limitations existing in our study. First, the number of patients of bone or lung metastasis was too small, so the insufficient sample size might lead to large bias and unconvincing results. Second, this study is a kind of retrospective study which might have selection bias because not all the GIST patients had routine tests for metastasis, under which circumstance the incidence of metastasis might be underestimated. Finally, although there were studies that reported that KIT mutation-positive and DOG1-negative cases indicated a tendency of higher rate of tumor metastasis $[17,19]$ and no relationship was found between PDGFRA mutation and metastasis [19], the SEER database did not provide such information about the status of KIT, DOG1, and PDGFRA, which are all the important immunohistochemical markers for GIST diagnosis and prognosis. Anyway, regardless of these limitations, it is the first study to discuss the potential relationship of liver metastasis and bone or lung metastasis and it also provide possible elements to estimate survival from external and macroscopic aspect in the population. We wish our study could be helpful for clinical diagnosis and treatment of GIST.

\section{Conclusions}

In conclusion, our results suggested that liver metastasis might not influence bone or lung metastasis. The patients with metastasis of liver, bone, or lung had a lower survival than those without and liver might play a dominant role in the prognosis of patients with metastasis instead of the other two sites. Moreover, age, sex, marital status and surgery were all significant prognostic factors for patients with liver metastasis. Therefore, clinical diagnosis and treatment should pay more attention to the liver status and further studies are needed to explore the metastatic pattern of GIST.

Acknowledgements The project was supported by the Natural Science Foundation of Hunan Province, China (Grant No. 2018JJ6065). All the authors have made joint effort to complete this research.

\section{Compliance with ethical standards}

Conflict of interest All the authors declare they have no conflict of interest.

Ethical approval This article does not contain any studies with human participants or animals performed by any of the authors. It has been permitted to obtain the data from SEER database (Reference Number 14660-Nov2017).

Informed consent For this type of study, formal consent is not required.

Open Access This article is distributed under the terms of the Creative Commons Attribution 4.0 International License (http://creativeco mmons.org/licenses/by/4.0/), which permits unrestricted use, distribution, and reproduction in any medium, provided you give appropriate credit to the original author(s) and the source, provide a link to the Creative Commons license, and indicate if changes were made.

\section{References}

1. Acar T, Efe D, Okus A, Ocal I, Harman M. A rare solid tumor of the retroperitoneum with venous extension and lung metastasis: extra-gastrointestinal stromal tumo. Turk J Gastroenterol Off J Turk Soc Gastroenterol. 2015;26:358-9. https://doi.org/10.5152/ tjg.2015.0149.

2. Aizer AA, et al. Multidisciplinary care and pursuit of active surveillance in low-risk prostate cancer. J Clin Oncol Off $\mathbf{J}$ Am Soc Clin Oncol. 2012;30:3071-6. https://doi.org/10.1200/ jco.2012.42.8466.

3. Aktan M, Koc M, Yavuz BB, Kanyilmaz G. Two cases of gastrointestinal stromal tumor of the small intestine with liver and bone metastasis. Ann Transl Med. 2015;3:259. https://doi. org/10.3978/j.issn.2305-5839.2015.09.46.

4. Bauer S, et al. Long-term follow-up of patients with GIST undergoing metastasectomy in the era of imatinib: analysis of prognostic factors (EORTC-STBSG collaborative study). Eur J Surg Oncol J Eur Soc Surg Oncol Br Assoc Surg Oncol. 2014;40:4129. https://doi.org/10.1016/j.ejso.2013.12.020.

5. Breccia $\mathrm{M}$, et al. Age influences initial dose and compliance to imatinib in chronic myeloid leukemia elderly patients but concomitant comorbidities appear to influence overall and event-free survival. Leuk Res. 2014;38:1173-6. https://doi.org/10.1016/j. leukres.2014.06.020.

6. Burkill GJ, Badran M, Al-Muderis O, Meirion Thomas J, Judson IR, Fisher C, Moskovic EC. Malignant gastrointestinal stromal tumor: distribution, imaging features, and pattern of metastatic spread. Radiology. 2003;226:527-32. https://doi.org/10.1148/ radiol.2262011880.

7. Chen M, Wang X, Wei R, Wang Z. The influence of marital status on the survival of patients with operable gastrointestinal stromal tumor: A SEER-based study. Int J Health Plan Manag. 2018. https ://doi.org/10.1002/hpm.2661. 
8. DeMatteo RP, Lewis JJ, Leung D, Mudan SS, Woodruff JM, Brennan MF. Two hundred gastrointestinal stromal tumors: recurrence patterns and prognostic factors for survival. Ann Surg. 2000;231:51-8.

9. DeMatteo RP, Shah A, Fong Y, Jarnagin WR, Blumgart LH, Brennan MF. Results of hepatic resection for sarcoma metastatic to liver. Ann Surg. 2001;234:540-7 (discussion 547-548).

10. Demetri GD, et al. NCCN Task Force report: update on the management of patients with gastrointestinal stromal tumors. J Natl Compr Cancer Netw JNCCN. 2010;2(8 Suppl):S1-41 (quiz S42-S44).

11. Farag S, et al. Elderly patients with gastrointestinal stromal tumour (GIST) receive less treatment irrespective of performance score or comorbidity - A retrospective multicentre study in a large cohort of GIST patients. Eur J Cancer (Oxford, England: 1990). 2017;86:318-25. https://doi.org/10.1016/j.ejca.2017.09.017.

12. Gaitanidis A, Alevizakos M, Tsaroucha A, Simopoulos C, Pitiakoudis M. Incidence and predictors of synchronous liver metastases in patients with gastrointestinal stromal tumors (GISTs). Am J Surg. 2018;216:492-7. https://doi.org/10.1016/j.amjsu rg.2018.04.011.

13. Ghanem N, et al. Computed tomography in gastrointestinal stromal tumors. Eur Radiol. 2003;13:1669-78. https://doi. org/10.1007/s00330-002-1803-6.

14. Goldzweig G, Andritsch E, Hubert A, Brenner B, Walach N, Perry S, Baider L. Psychological distress among male patients and male spouses: what do oncologists need to know? Annals of oncology: official journal of the European Society for Medical Oncology. 2010;21:877-83. https://doi.org/10.1093/annonc/mdp398.

15. Gomez SL, et al. Effects of marital status and economic resources on survival after cancer: a population-based study. Cancer. 2016;122:1618-25. https://doi.org/10.1002/cncr.29885.

16. Jati A, Tatli S, Morgan JA, Glickman JN, Demetri GD, Van den Abbele A, Silverman SG. Imaging features of bone metastases in patients with gastrointestinal stromal tumors. Diagn Interv Radiol (Ankara, Turkey). 2012;18:391-6. https://doi.org/10.4261/13053825.dir.5179-11.1.

17. Jiang Z, Zhang J, Li Z, Liu Y, Wang D, Han G. A meta-analysis of prognostic value of KIT mutation status in gastrointestinal stromal tumors. OncoTargets Ther. 2016;9:3387-98. https://doi. org/10.2147/OTT.S101858.

18. Joensuu H, Hohenberger P, Corless CL. Gastrointestinal stromal tumour. Lancet (London, England). 2013;382:973-83. https://doi. org/10.1016/s0140-6736(13)60106-3.

19. Jung SH, Suh KS, Kang DY, Kang DW, Kim YB, Kim ES. Expression of DOG1, PDGFRA, and p16 in gastrointestinal stromal tumors. Gut Liver. 2011;5:171-80. https://doi.org/10.5009/ gnl.2011.5.2.171.

20. Kalkmann J, et al. Consensus report on the radiological management of patients with gastrointestinal stromal tumours (GIST): recommendations of the German GIST imaging working group. Cancer Imag Off Pub Int Cancer Imag Soc. 2012;12:126-35. https ://doi.org/10.1102/1470-7330.2012.0013.

21. Karakousis GC, Singer S, Zheng J, Gonen M, Coit D, DeMatteo RP, Strong VE. Laparoscopic versus open gastric resections for primary gastrointestinal stromal tumors (GISTs): a size-matched comparison. Ann Surg Oncol. 2011;18:1599-605. https://doi. org/10.1245/s10434-010-1517-y.

22. Katz SC, DeMatteo RP. Gastrointestinal stromal tumors and leiomyosarcomas. J Surg Oncol. 2008;97:350-9. https://doi. org/10.1002/jso.20970.
23. Lamba G, Gupta R, Lee B, Ambrale S, Liu D. Current management and prognostic features for gastrointestinal stromal tumor (GIST) Exp. Hematol Oncol. 2012;1:14. https://doi. org/10.1186/2162-3619-1-14.

24. Miettinen M, Lasota J. Gastrointestinal stromal tumors: pathology and prognosis at different sites. Semin Diagn Pathol. 2006;23:70-83.

25. Miettinen M, Lasota J. Gastrointestinal stromal tumors. Gastroenterol Clin North Am. 2013;42:399-415. https://doi.org/10.1016/j. gtc.2013.01.001.

26. Nilsson B, et al. Gastrointestinal stromal tumors: the incidence, prevalence, clinical course, and prognostication in the preimatinib mesylate era-a population-based study in western Sweden. Cancer. 2005;103:821-9. https://doi.org/10.1002/cncr.20862.

27. Osborne C, Ostir GV, Du X, Peek MK, Goodwin JS. The influence of marital status on the stage at diagnosis, treatment, and survival of older women with breast cancer. Breast Cancer Res Treat. 2005;93:41-7. https://doi.org/10.1007/s10549-005-3702-4.

28. Shima Y, et al. Aggressive surgery for liver metastases from gastrointestinal stromal tumors. J Hepato Biliary Pancreat Surg. 2003;10:77-80. https://doi.org/10.1007/s10534-002-0813-9.

29. Sircar K, Hewlett BR, Huizinga JD, Chorneyko K, Berezin I, Riddell RH. Interstitial cells of Cajal as precursors of gastrointestinal stromal tumors. Am J Surg Pathol. 1999;23:377-89.

30. Song W, Tian C. The effect of marital status on survival of patients with gastrointestinal stromal tumors: a SEER database analysis. Gastroenterol Res Pract. 2018;2018:5740823. https://doi. org/10.1155/2018/5740823.

31. Soreide K, Sandvik OM, Soreide JA, Giljaca V, Jureckova A, Bulusu VR. Global epidemiology of gastrointestinal stromal tumours (GIST): A systematic review of population-based cohort studies. Cancer Epidemiol. 2016;40:39-46. https://doi. org/10.1016/j.canep.2015.10.031.

32. Suster S. Gastrointestinal stromal tumors. Semin Diag Pathol. 1996;13:297-313.

33. Tanaka H, Yamazaki N, Watanabe H, Nakade M. Gastrointestinal stromal tumor with metastasis of chest wall and both lungs Kyobu geka. Jpn J Thorac Surg. 2017;70:434-7.

34. Tran T, Davila JA, El-Serag HB. The epidemiology of malignant gastrointestinal stromal tumors: an analysis of 1,458 cases from 1992 to 2000. Am J Gastroenterol. 2005;100:162-8. https://doi. org/10.1111/j.1572-0241.2005.40709.x.

35. Vassos N, Agaimy A, Hohenberger W, Croner RS. Extraabdominal lymph node metastasis in gastrointestinal stromal tumors (GIST). J Gastrointest Surg Off J Soc Surg Aliment Tract. 2011;15:12326. https://doi.org/10.1007/s11605-011-1464-3.

36. Vassos N, Agaimy A, Hohenberger W, Croner RS. Management of liver metastases of gastrointestinal stromal tumors (GIST). Ann Hepatol. 2015;14:531-9.

37. Waterman BR, Kusnezov N, Dunn JC, Hakim MN. Aggressive gastrointestinal stromal tumor with spinal metastases: a case report. Mil Med. 2015;180:e618-21. https://doi.org/10.7205/ milmed-d-14-00552.

Publisher's Note Springer Nature remains neutral with regard to jurisdictional claims in published maps and institutional affiliations. 